Research

\title{
Feeding and resting behaviour of malaria vector, Anopheles arabiensis with reference to zooprophylaxis Aneth Mahande ${ }^{1}$, Franklin Mosha ${ }^{1}$, Johnson Mahande ${ }^{3}$ and Eliningaya Kweka*1,2
}

Address: ${ }^{1} \mathrm{KCM}$ College of Tumaini University, PO BOX 2240, Moshi, Tanzania, ${ }^{2}$ Ifakara Health Research and Development Centre, Department of Public Health Entomology, PO BOX 53, Ifakara-Morogoro, Tanzania and ${ }^{3}$ Kilimanjaro Christian Medical Center Ophthalmology Department, PO BOX 2240, Moshi Tanzania

Email: Aneth Mahande - anethf@yahoo.co.uk; Franklin Mosha - fwmosha@hotmail.com; Johnson Mahande - jmmahande@yahoo.com; Eliningaya Kweka* - pat.kweka@gmail.com

* Corresponding author

Published: 30 July 2007

Malaria Journal 2007, 6:100 doi:10.1186/1475-2875-6-100

This article is available from: http://www.malariajournal.com/content/6/1/100

(c) 2007 Mahande et al; licensee BioMed Central Ltd.

This is an Open Access article distributed under the terms of the Creative Commons Attribution License (http://creativecommons.org/licenses/by/2.0), which permits unrestricted use, distribution, and reproduction in any medium, provided the original work is properly cited.

\section{Abstract}

Background: The most important factor for effective zooprophylaxis in reducing malaria transmission is a predominant population of a strongly zoophilic mosquito, Anopheles arabiensis. The feeding preference behaviour of Anopheline mosquitoes was evaluated in odour-baited entry trap (OBET).

Methods: Mosquitoes were captured daily using odour-baited entry traps, light traps and hand catch both indoor and in pit traps. Experimental huts were used for release and recapture experiment. The mosquitoes collected were compared in species abundances.

Results: Anopheles arabiensis was found to account for over $99 \%$ of Anopheles species collected in the study area in Lower Moshi, Northern Tanzania. In experimental release/capture trials conducted at the Mabogini verandah huts, An. arabiensis was found to have higher exophilic tendency (80.7\%) compared to Anopheles gambiae (59.7\%) and Culex spp. (60.8\%). OBET experiments conducted at Mabogini collected a total of 506 An. arabiensis in four different trials involving human, cattle, sheep, goat and pig. Odours from the cattle attracted $90.3 \%$ (243) compared to odours from human, which attracted $9.7 \%(26)$ with a significant difference at $\mathrm{P}=$ 0.005. Odours from sheep, goat and pig attracted $9.7 \%, 7.2 \%$ and $7.3 \%$, respectively. Estimation of $\mathrm{HBI}$ in An. arabiensis collected from houses in three lower Moshi villages indicated lower ratios for mosquitoes collected from houses with cattle compared to those without cattles. $\mathrm{HBI}$ was also lower in mosquitoes collected outdoors (0.1-0.3) compared to indoor (0.4-0.9).

Conclusion: In discussing the results, reference has been made to observation of exophilic, zoophilic and feeding tendencies of An. arabiensis, which are conducive for zooprophylaxis. It is recommended that in areas with a predominant An. arabiensis population, cattle should be placed close to dwelling houses in order to maximize the effects of zooprophylaxis. Protective effects of human from malaria can further be enhanced by keeping cattle in surroundings of residences. 


\section{Background}

Host-odours play a major role in the orientation of nocturnal mosquitoes towards their hosts [1]. Differences in host-preference between mosquito species are, therefore, likely to be reflected in their response to different host odours offered [2]. Carbon dioxide is a major component of the breath of all warm-blooded vertebrates and has been studied intensively for its attractiveness to mosquitoes $[3,4]$. A number of studies have confirmed the role of $\mathrm{CO}_{2}$ in the host-seeking behaviour of the highly anthropophilic Anopheles gambiae s.s [4].

Members of the An. gambiae complex are important malaria vectors in sub-Saharan Africa, but these species differ strongly in host-preference [5] which is assumed to be stimulated by the odour produced by the host [6]. Anopheles arabiensis occupies over $70 \%$ of sub-Saharan Africa; the species dominates in arid zones and some of highland areas $[7,8]$ and adapts to endophagic and endophilic patterns, where hosts are domestic and indoor, but adopts exophagic patterns where hosts are mainly outdoors. In response to indoor spraying, they become completely exophilic [9-11].

There have been reports of instances where the introduction of livestock has apparently reduced prevalence of the disease, the reduction in malaria that occurred in Europe and in United States earlier last century has been attributed partly to the increase in livestock numbers [12].

Anopheles arabiensis has a low Human Blood Index (HBI) and shows a marked preference for cattle and other warmblooded animals [13]. It has a high degree of zoophily in Madagascar as demonstrated by HBI reported from various environmental settings $[8,14,15]$. Lower proportion of human blood meals (26\%) were recorded in An. arabiensis collected from sites where cattle were kept closer to human housing than in those collected from sites where cattle were kept some distance from humans $(57 \%)[16,17]$

The behaviour of An. arabiensis was assessed in this paper by using three different ways. First by using experimental huts, where the resting behaviour of An. arabiensis was assessed and compared with other species common in the community (An. gambiae and Culex quinquefasciatus). Second by using odour-baited entry traps: OBETs (see figure 1) involving humans and four different animals usually kept in the community (cattle, goats, sheeps and pigs). Mosquito behaviour was also assessed by using HBI comparing the feeding behaviour of mosquitoes in three different communities.

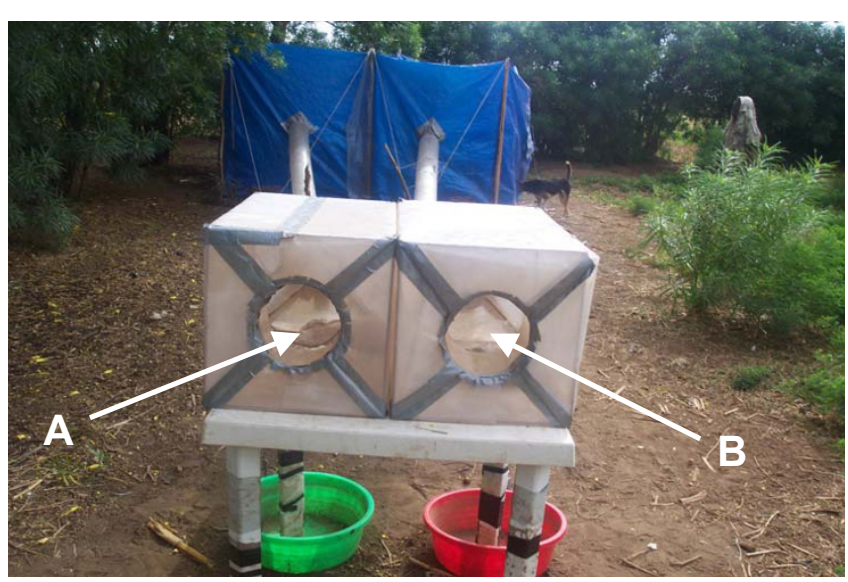

Figure I

Odour Baited Entry Traps (OBETs) from the tents with different baits. Trap A with a cattle and B with human, both of the same weight.

This paper describes the results of a study of the response of An. arabiensis to humans, cattle, goat, sheep and pig in lower Moshi, Northern Tanzania.

\section{Methods}

\section{Study Area}

Mabogini, Rau and Mtakuja villages were selected for this study. These villages are in Lower Moshi, Northern Tanzania, at an altitude of about $800 \mathrm{~m}$ above sea level within Maasai savannah at the foothills of Mount Kilimanjaro. Four houses in each selected village were randomly selected for Light Trap Catches (LTC) and Pyrethrum Spray Catches (PSC). OBET experiments were also conducted close to a dwelling house at Mabogini, Lower Moshi area.

\section{Animals for experiments}

Animals were taken from the villagers who volunteered during the experiments after the consent procedures.

\section{Assessment of An. arabiensis resting habit}

This was done by assessing exophilic tendencies of $A n$. arabiensis in comparison with An. gambiae s.s and Culex quinquefasciatus. The huts were a slight modified from those of Verandah Trap Huts (VTH) described by Smith[18].

\section{Assessment of An. arabiensis host preference}

This was done by estimation of relative attractiveness of man and livestock to An. arabiensis. The technique was designed to simulate natural condition as far as possible. This experiment was done in two phases as follows:- 


\section{a) Odour Baited Entry Traps (OBETs)}

The experimental arrangement was similar to that of Costantini et al [19] and Duchemin et al [20]. Two OBETs, designed to catch host-seeking mosquitoes responding mainly to odour cues, were placed next to one another near to a residential compound at Mabogini village. The OBETs were similar to lobster-pot entry traps and baited with test host. Odours were drawn from reservoir bait in a tent to the trap by a fan. They were set approximately 1.5 $\mathrm{m}$ high on wooden tables. Air coming from two tents standing approximately $7 \mathrm{~m}$ upwind of the traps was drawn into the OBETs by fans via plastic air ducts. Mosquitoes had a choice of odours from two alternative hosts presented to the approaching mosquitoes.

One adult man and a calf of similar mass were concealed in two separate tents and their odour drawn by fans to the OBETs via inflatable 'lay-flat' polythene tubing. The calf, a zebu breed, was tethered inside a small fence and covered with the polyethylene tent. On any trapping night, the OBETs were operated from 19.00 to 05.00 a.m. After every two days the traps were exchanged from side to side in order to compensate for any positional effects. Subsequently, other domestic animals were also placed in the two different tents where mosquitoes preferences were assessed between a calf (50 kg) and three goats (15 kg each), three sheeps (15 kg. each) and lastly three pigs (15 kg each).

\section{b) Estimation of Human Blood Indices (HBI) of An. arabiensis collected from three different villages}

The pyrethrum spray-catch method is fully described in the WHO entomology manual [21]. In each house, a bedroom that was occupied by one sleeper was selected for the mosquitoes collection. Out of the selected four houses in each village, two had livestock and other two had no livestock.

Outdoor resting mosquitoes were collected by standard methods involving pit traps and empty drums [22]. Four pit traps were constructed in each village and four tanks drums placed in each village. The pyrethrum spray catch was done by covering the floor and furniture in bedrooms with white sheets. The room was then sprayed with pyrethrum ( $0.4 \%$ volume diluted in kerosene). After 10 minutes, the knocked-down mosquitoes were collected from the white sheets as described in WHO entomology manual [21] and Premasiri et al [23].

Light trap collection was done by suspending a light trap with its base at $45 \mathrm{~cm}$ above the head of a person sleeping under intact bednet. Light trap was operated from 18:30 to $06: 30$. Collection of mosquitoes from the trap was performed as described [21]. Identification of blood meal source was carried out according to methods described by Bray et al [24].

\section{Data analysis}

The data entry was done in Microsoft Excel 2000 and analysis was carried out using statistical package for social science (SPSS) version 10 programme. The significance test was estimated assuming an $\alpha$ (two sided) $=0.05$ ). Other data were analysed by using EpiInfo ${ }^{\mathrm{TM}}$ Version 3.2.2 programme where $\chi^{2}$ and $P$ value were calculated.

\section{Ethical considerations}

Before conducting this study, ethical clearance was sought from Kilimanjaro Christian Medical College Research Ethics Committee. Permission from the district and respective village authorities was obtained. Both verbal and written informed consent was obtained from the head of the households selected for the study.

\section{Results}

During the study in experimental huts the exophily pattern and feeding behaviour of An. arabiensis was assessed.

\section{An. arabiensis resting habits}

A total of 930 mosquitoes were released into the experimental hut. Out of these, 81 were lost (could not be recovered) during the experiment and were removed from the analysis. Therefore, 849 mosquitoes were used in the data analysis. Of these $31.8 \%$ (270) were An. arabiensis, $35.1 \%$ (298) were An. gambiae s.s and $33.1 \%$ (281) were Culex spp.

These results have shown that, An. arabiensis had higher exophilic tendency (80.7\%) compared to An. gambiae s.s $(59.7 \%)$ and Culex spp (60.8\%) as in Figure 2. The difference was statistically significant $\left(\chi^{2}=23, \mathrm{P}=0.001\right)$.

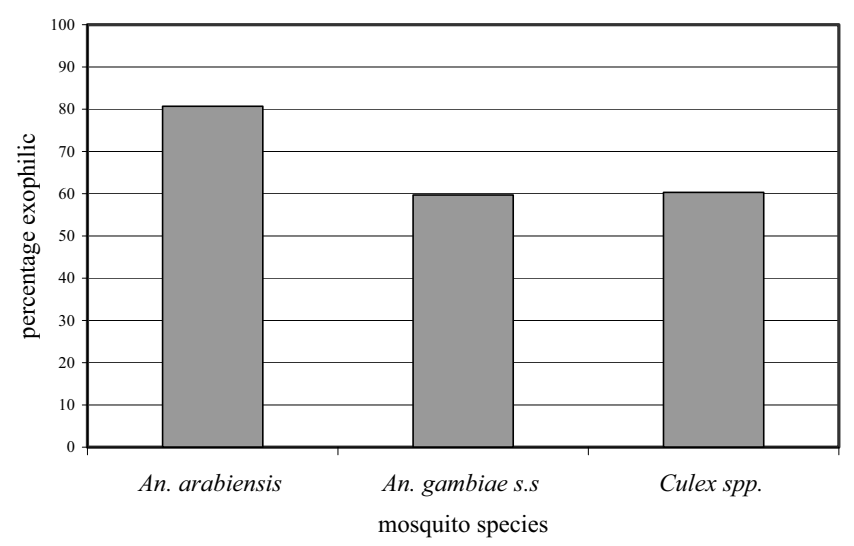

Figure 2

The exophilic behaviour of three mosquito species in experimental huts. 


\section{OBETs experiments}

During the period of this study, An. arabiensis was the predominant species (79.5\%) followed by Culex quinquefasciatus as shown in Table 1. Anopheles funestus accounted for $0.55 \%$ of the outdoor and indoor collected mosquitoes.

The OBETs collected a total of 506 female An. arabiensis in four different experiments (where different baits in separate tent were compared to cattle). The greatest numbers of mosquitoes were collected from cattle traps compared to human, goat, pig and sheep traps (Figure 3).

\section{Experiment l: Cattle versus human}

Two hundred and sixty nine female An. arabiensis mosquitoes were collected from the two traps. Of these $90.3 \%$ (243) were collected from the cattle odour trap and $9.7 \%$ (26) from human odour trap.

\section{Experiment II: Cattle versus sheep}

Thirty-one An. arabiensis mosquitoes were collected. Only $9.7 \%$ (3) were collected in the sheeps odour trap and the rest $90.3 \%$ (28) were collected in the cattle odour trap.

\section{Experiment III: Cattle versus goat}

A total of $83 \mathrm{An}$. arabiensis mosquitoes were collected. Higher proportion (92.8\%) was collected from cattle trap compared to that collected from goat trap (7.2\%).

\section{Experiment IV: Cattle versus Pig}

One hundred and twenty three An. arabiensis were collected in cattle and pigs traps. Of these $92.7 \%$ (114) and $7.3 \%$ (9) were collected from cattle and pig trap respectively.

\section{Results from experimental hut showing feeding preference} Zoophilic tendency of An. arabiensis mosquito was assessed during the host rotation in the experimental hut where treated cattle, untreated cattle and human were rotated in the huts. More blood-fed mosquitoes were col-

Table I: Mosquitoes collected from indoor (hand catch) and outdoors (pit trap) methods during the OBETs experiment in the study area.

\begin{tabular}{lccc}
\hline Specie type & Method of collection & Number & percentage \\
\hline \multirow{3}{*}{ An. arabiensis } & Indoor & 184 & 25.7 \\
& Outdoor & 533 & 74.3 \\
& Total & 717 & \\
An. funestus & Indoor & 5 & 100 \\
& Outdoor & 0 & 0 \\
Culex spp. & Total & 5 & \\
& Indoor & 41 & 22.8 \\
Total & Outdoor & 139 & 77.2 \\
& Total & 180 & \\
& & 902 & \\
\hline
\end{tabular}

lected from hut with untreated cattle $($ Mean $=22.5)$ than from hut with human sleepers $($ mean $=9.0)$.

\section{Human blood indices}

A total of 3,902 mosquitoes were collected from indoors using pyrethrum spray-catch, outdoors using pit trap and empty drums in study villages, namely Mabogini, Rau and Mtakuja. Among these 1,792 were An. arabiensis, 2,093 were Culex spp. and 17 were An. funestus. Of the collected An. arabiensis mosquitoes only 417 were blood-fed and were tested for Human Blood Index (HBI).

The results indicated that in all of the three villages, lower HBI were observed in mosquitoes collected indoors (0.40.7 ) and outdoor (0-0.1) from households with cattle compared to those households with no cattle.

\section{Discussion}

The experimental hut studies confirm that An. arabiensis has a tendency to escape from houses after feeding, a behavioural pattern normally referred to as exophily. This behaviour was also shown by Smith[25] in the Umbugwe area (now called Magugu) of Northern Tanzania. The exophily rate for $C x$. quinquefasciatus $(60.8 \%)$ and An. arabiensis $(80.7 \%)$ observed in this study is similar to observations made by Kulkarni et al [26]. Percentage of mosquitoes which escaped through the eaves and windows of the experimental huts on the following morning after entry into the control huts were $70.9 \%(n=3,664)$ An. arabiensis compared to $66.0 \%(n=2,075) C x$. quinquefasciatus. Elsewhere in East Africa, Highton et al [27] reported that An. arabiensis in the Kisumu area, Kenya,

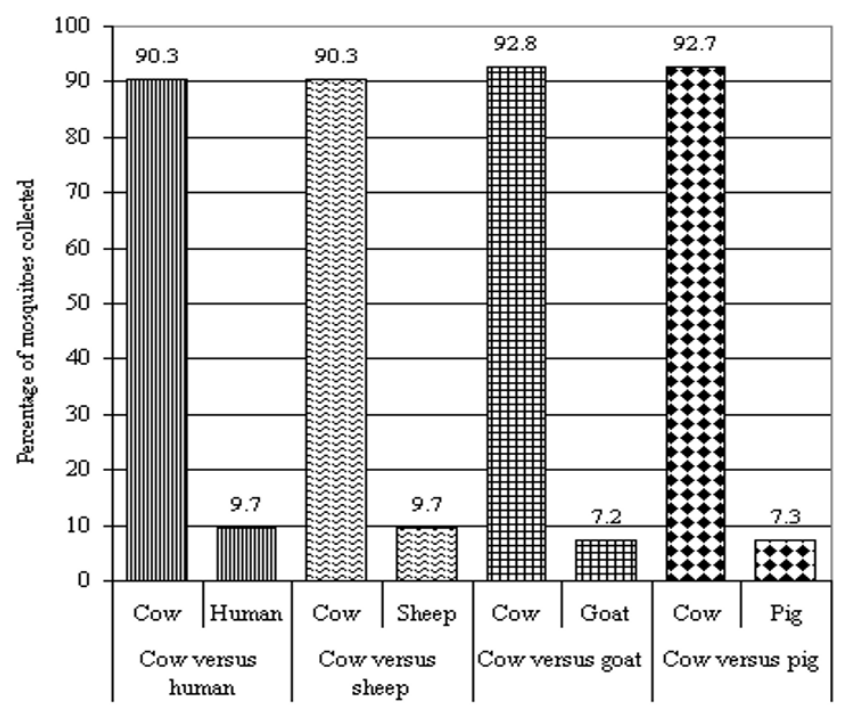

Figure 3

Anopheles arabiensis collected from OBETs with human and different animals. 
showed a tendency to occur outdoors 2.2 times more frequently than indoors, while Joshi et al [28] reported 2.8 times. White et al [5] observed that in Segera, Tanzania, An. arabiensis displayed a 2.3 times greater tendency to occur outdoors compared to An. gambiae s.s.

The exophilic behaviour demonstrated by An. arabiensis should be taken into consideration when planning control strategies. Residual house spraying will, therefore, have little impact in areas with a predominant An. arabiensis population since the targeted vector will not spend enough time on sprayed walls to pick up the lethal insecticide dose.

Anopheles arabiensis was found to be the predominant mosquito species at lower Moshi, accounting for $79.5 \%$ of the total mosquito population and $99.3 \%$ of Anopheline species. The study villages are in semi-arid belt and similar observations have been reported previously from the same area [29] and elsewhere in Africa [5,30,31]. The OBETs experiments showed a very strong attraction of $A n$. arabiensis to cattle odour. When compared to human and other livestock such as sheep, pig and goat, the cattle attracted over $90 \%$ of the collected An. arabiensis. Similar findings with the OBETs have also been reported by Duchemin et al [20] in Madagascar and by Diatta et al [32] in Senegal. The unattractive natures of odour from goat and pig have not been reported before.

Strong zoophilic tendencies of An. arabiensis have also been observed elsewhere including Mwea irrigation area in Kenya [8]. The present studies have demonstrated the protective effect of cattle against mosquito bites. A lower proportion of An. arabiensis collected from houses with cattle were found to have fed on humans as indicated by low HBI compared to houses without cattle. Similar findings have been reported elsewhere $[8,14,33,34]$. These results contradict reported observations that proximity of cattle to humans increases mosquito bites on humans $[13,35,36]$. This could have been due to differences in species and environmental conditions in those areas.

In this study area, the OBETs and experimental hut studies as well as HBI community observations provide strong evidence that cattle kept around dwelling houses are effective at offering protection against $A n$. arabiensis bites and consequently reduces malaria incidences. This is regardless of other factors such as cattle-human ratio and proximity of animals to mosquito breeding sites as postulated by Saul [37].

\section{Competing interests}

The author(s) declare that they have no competing interests.

\section{Authors' contributions}

AMM and FWM Co-designed the study, participated in analysis and interpretation of data and contributed to the drafting of the manuscript. JMM carried out the analysis of mosquitoes assisted with data analysis and interpretation and was involved in the drafting of the manuscript. EJK coordinated the study, participated in the analysis and interpretation of results, and designed the first draft and final version of the manuscript and critically evaluation thereof. All authors read and approved the final manuscript.

\section{Acknowledgements}

The study was funded by Belgium Technical co-operation as part of MSc scholarship for AMM. Augustine Mtui and Charles Massenga are highly appreciated for assisting in the field activities. This work would not have been a success without participation of the communities of Mtakuja and Rau Kati villages, their cooperation is highly appreciated. The authors are thankful for valuable critical comments from two reviewers (Dr. Rose Nathan of IHRDC and Rose Mwangi of JMP).

\section{References}

I. Takken W, Kline DL: Carbon dioxide and I-octen-3-ol as mosquito attractants. J Am Mosq Control Assoc 1989, 5(3):3। I-316.

2. Gillies MT: The role of carbon dioxide in host-finding by mosquitoes (Diptera: Culicidae): a review. Bull Entomol Res 1980, 70:525-532.

3. Mukabana WR, Takken W, Killeen GF, Knols BG: Allomonal effect of breath contributes to differential attractiveness of humans to the African malaria vector Anopheles gambiae. Malar J 2004, 3:I.

4. Qiu YT, Smallegange RC, Hoppe S, van Loon JJ, Bakker EJ, Takken W: Behavioural and electrophysiological responses of the malaria mosquito Anopheles gambiae Giles sensu stricto (Diptera: Culicidae) to human skin emanations. Med Vet Entomol 2004, 18:429-438.

5. White GB, Magayuka SA, Boreham PFL: Comparative studies on sibling species of the Anopheles gambiae Giles complex (Diptera: Culicidae): bionomics and vectorial activity of species $A$ and species B at Segera, Tanzania. Bull Entomol Res 1974, 62:215-317.

6. Knols BGJ: Odour-mediated host-seeking behaviour of the Afro-tropical malaria vector Anopheles gambiae Gilles. In PhD Thesis University of Wageningen, The Netherlands; 1996:213.

7. Onyabe DY, Conn JE: Population genetic structure of the malaria mosquito Anopheles arabiensis across Nigeria suggests range expansion. Mol Ecol 200 I, 10:2577-259I.

8. Mutero CM, Kabutha C, Kimani V, Kabuage L, Gitau G, Ssennyonga J, Githure J, Muthami L, Kaida A, Musyoka L, et al.: A transdisciplinary perspective on the links between malaria and agroecosystems in Kenya. Acta Trop 2004, 89:17I-I86.

9. Coluzzi M, Sabatini A, Petrarca V, Di Deco MA: Chromosomal differentiation and adaptation to human environments in the An. gambiae complex. Trans R Soc Trop Med Hyg 1979, 73:483-497.

10. Ameneshewa $B$, Service $M W$ : The relationship between female body size and survival rate of the malaria vector Anopheles arabiensis in Ethiopia. Med Vet Entomol 1996, 10:170-172.

II. Mendis C, Jacobsen JL, Gamage-Mendis A, Bule E, Dgedge M, Thompson R, Cuamba N, Barreto J, Begtrup K, Sinden RE, Bøgh : Anopheles arabiensis and An. funestus are equally important vectors of malaria in Matola coastal suburb of Maputo, southern Mozambique. Med Vet Entomol 2000, 14:171-180.

12. Bruce-Chwatt LJ: Essential Malariology. second edition. London: William Heinemann Medical Books; 1985.

13. Habtewold T, Prior A, Torr JS, Gibson G: Could Insecticidetreated cattle reduce Afrotropical malaria transmission? Effects of deltamethrin-treated zebu on Anopheles arabiensis behaviour and survival in Ethiopia. Med Vet Entomol 2004, 18:408-4I 7. 
14. Ralisoa RBO, Coluzzi M: Genetical investigations on zoophilic and exophilic Anopheles arabiensis from Antananarivo area (Madagascar). Parassitologia 1987, 29:93-97.

15. Fontenille D, Lepers JP, Coluzzi M, Campbell GH, Rakotoarivony I, Coulanges P: Malaria transmission and vector biology on sainte Marie Island, Madagascar. J Med Entomol 1992, 29:197-202.

16. Seyoum A, Balcha F, Balkew M, Ali A, Gebre-Michael T: Impact of cattle keeping on human biting rate of Anopheline mosquitoes and malaria transmission around Ziway, Ethiopia. East Afr Med J 2002, 79(9):485-490.

17. Githeko AK, Service MW, Mbogo CM, Atieli FK, Juma FO: Origin of blood meals in indoor and outdoor resting malaria vectors in western Kenya. Acta Trop 1994, 58:307-316.

18. Smith $A: A$ review of the origin and development of experimental hut techniques used in the study of insecticides in East Africa. E Afr Med J 1964, 41:361-374.

19. Costantini C, Sagnon NF, Della Torre A, Diallo M, Brady J, Gibson G, Coluzzi M: Odour-mediated host preferences of West African mosquito with particular reference to malaria vectors. $A m \mathrm{~J}$ Trop Med Hyg 1998, 58:56-63.

20. Duchemin JB, Tsy JM, Rabarison P, Roux J, Coluzzi M, Costantini C: Zoophily of Anopheles arabiensis and An. gambiae in Madagascar demonstrated by odour-baited entry traps. Med Vet Entomol 200I, I5(I):50-57.

21. WHO: Manual on practical entomology in Malaria part 2: methods and techniques. Geneva: World health Organisation; 1975.

22. Rozendaal JA: Vector Control: Methods for use by Individuals and Communities. Geneva: World Health Organisation; 1997.

23. Premasiri DA, Wickremasinghe AR, Premasiri DS, Karunaweera N: Malarial vectors in an irrigated rice cultivation area in southern Sri Lanka. Trans R Soc Trop Med Hyg 2005, 99: I06-I I4.

24. Bray RS, Gill GS, Killick-kendrick R: Current and possible future technique for the identification of bloodmeals of vector haematophagous arthropods. World Health Organisation; 1984.

25. Smith A: The preferential indoor resting habitats of Anopheles gambiae in the Umbugwe area of Tanganyika. East Afr Med J 1962, 39:631-635.

26. Kulkarni MA, Kweka EJ, Nyale E, Lyatuu E, Mosha FW, Chandramohan D, Rau ME, Drakeley C: Entomological evaluation of malaria vectors at different altitudes in Hai district, northeastern Tanzania. J Med Entomol 2006, 43:580-588.

27. Highton RB, Bryan JH, Boreham PFL, Chandler JA: Studieson sibling species Anopheles gambiae Giles and Anopheles arabiensis Patton (Diptera: Culicidae) in the Kisumu area, Kenya. Bull Entomol Res 1979, 69:43-53.

28. Joshi GP, Service MW, Pradhan GD: A survey of species $\mathbf{A}$ and $\mathbf{B}$ of the Anopheles gambiae Giles complex in the Kisumu area of Kenya prior to insecticidal spraying with OMS-43 (Fenitrothion). Ann Trop Med Parasitol 1975, 69:91-104.

29. Ijumba JN, Mosha FW, Lindsay SW: Malaria transmission risk variations derived from different agricultural practices in an irrigated area of northern Tanzania. Med Vet Entomol 2002, 16:28-38.

30. Mosha FW, Petrarca V: Ecological studies on Anopheles gambiae complex sibling species on the Kenya coast. Trans $R$ Soc Trop Med Hyg 1983, 77:344-345.

31. Onyabe DY, Conn JE: The distribution of two major malaria vectors, Anopheles gambiae and Anopheles arabiensis, in Nigeria. Mem Inst Oswaldo Cruz 200I, 96: I08I-I 084.

32. Diatta M, Spiegel A, Lochouarn L, Fontenille D: Similar feeding preferences of Anopheles gambiae and An. arabiensis in Senegal. Trans R Soc Trop Med Hyg 1998, 92:270-272.

33. ljumba JN, Mwangi RW, Beier JC: Malaria transmission potential of Anopheles mosquitoes in the Mwea-Tebere irrigation scheme, Kenya. Med Vet Entomol 1990, 4:425-432.

34. Smith A: Outdoor cattle feeding and resting of An. gambiae Giles and A. pharoensis Theo. in the Pare-Taveta area of East Africa. East Afr Med J 1958, 35:559-567.

35. BØgh C, Clarke SE, Walraven GL, Lindsay SW: Zooprophylaxis, artifact or reality? A paired-cohort study of the effect of passive zooprophylaxis on malaria in the Gambia. Trans $R$ Soc Trop Med Hyg 2002, 96:593-596.

36. Hewitt S, Kamal M, Muhammad N, Rowland M: An entomological investigation of the likely impact of cattle ownership on malaria in an Afghan refugee camp in the North West Frontier Province of Pakistan. Med Vet Entomol 1994, 8:160-164.

37. Saul A: Zooprophylaxis or zoopotentiation: the outcome of introducing animals on vector transmission is highly dependent on the mosquito mortality while searching. Malar $J 2003$, 2:32.

Publish with BioMed Central and every scientist can read your work free of charge

"BioMed Central will be the most significant development for disseminating the results of biomedical research in our lifetime. "

Sir Paul Nurse, Cancer Research UK

Your research papers will be:

- available free of charge to the entire biomedical community

- peer reviewed and published immediately upon acceptance

- cited in PubMed and archived on PubMed Central

- yours - you keep the copyright

Submit your manuscript here:

http://www.biomedcentral.com/info/publishing_adv.asp 